\title{
Thermodynamic and Spreading Properties of Oil Blends as Mosquito Larvicides
}

\author{
D. F. LATONA \\ Landmark University, Department of Physical Sciences, Omu-Aran, Nigeria \\ d1latona@yahoo.com
}

Received 1 July 2014 / Accepted 16 July 2014

\begin{abstract}
Mosquito control has relied solely on the eradication of adult mosquitoes by the spraying of aerosol under closed doors and windows. Apart from the toxicity of the aerosol, this method has been found ineffective because mosquitoes are becoming resistant to these insecticides. Herein, adequate and effective method of mosquito control was investigated towards the elimination of mosquito at the larva stage by spraying oil mixtures on the aqueous breeding sites. These oil mixtures acting as larvicides: 'malaroil' was observed in this study to kill the larvae in the aquatic habitat by asphyxia within twenty minutes of application. The thermodynamic parameters of such oil blends were identified for domestic application for control of mosquito and its concomitant diseases.
\end{abstract}

Keywords: Mosquito larvicides, Malaria, Oil blends, Density

\section{Introduction}

Malaria is a disease identified mainly at the tropical belt of the world. There are probably more cases of malaria than of any other infections ${ }^{1}$. Anophelis mosquito is the vector responsible for the spreading of malaria among human population in the mosquito endemic zones of the world ${ }^{2}$.

Hyperendemic areas are found in central and South America, in North and Central Africa, in all countries bordering on the Mediterranean, and in the middle and far east of Asia ${ }^{3}$. In India it was estimated at mid $20^{\text {th }}$ century that malaria was still responsible for the death of about one million people annually. It is most common in the tropics because of the favourable climatic conditions for the breeding of mosquito, the transmission of the disease which is possible throughout the year. Symptom of malaria includes fever, shivering, arthralgia (joint pain), vomiting and convulsion ${ }^{4}$. Malaria has been found to cause cognitive impairments, especially in children. It causes anemia and brain damage in growing up children ${ }^{5}$.

\section{Experimental}

The oil blends were prepared from the following description:

Solvents: $\mathrm{SA}=$. Kerosene, GD = Diesel 
Solutes: GBI = Used engine oil, GB2 = Pure engine oil

Blends: $\mathrm{A}=\mathrm{SA}+\mathrm{GB} 1, \mathrm{~B}=\mathrm{SA}+\mathrm{GB} 2, \mathrm{C}=\mathrm{GD}+\mathrm{GBI}$

Oil blends A, B, C were prepared by mixing volume of solvents ranging from $0-250 \mathrm{~cm}^{3}$ with $250 \mathrm{~cm}^{3}$ of solute in Winchester bottles. Each mixture or blend were shaken vigorously to ensure proper mixing. Determinations of flow time of the blends were determined by using Ostwald viscometer and their densities were determined by the use of density bottle. The thermodynamic properties of mixing were obtained from the below equations ${ }^{6}$ :

$$
\begin{aligned}
X_{\mathrm{m} 1} & =\frac{m_{1}}{m_{T}}=\frac{m_{1}}{m_{1}+m_{2}} \\
X_{m 2} & =\frac{m_{2}}{m_{T}}=\frac{M_{2}}{m_{1}+m_{2}} \\
\Delta G^{m} & =m_{T} R T\left(X_{m 1} \operatorname{In} X_{m 1}+X_{m 2} \operatorname{InX} X_{m 2}\right) \\
\Delta S^{m} & =-m_{T} R\left(X_{m 1} \ln X_{m 1}+X_{m 2} \operatorname{In} X_{m 2}\right)
\end{aligned}
$$

The spreading properties of oil blends on water surface were determined filling a beaker of a liter capacity to the brim with water and about seven drops of oil blend were allowed to under gravity on water surface and the spreading diameter was monitored at one minute interval as the droplet spreads on the water surface. The measurement was done by the use of a transparent ruler. Moreover, an aquarium of capacity $72000 \mathrm{~cm}^{3}$ was filled with tap water.

About ten mosquito larvae were introduced into the water, the larvae were allowed to acclimatise for about 24 hours, then oil blends were introduced onto the surface of the water. Hence, extinction time of the larvae by asphyxia were recorded.

\section{Results and Discussion}

Figure 1 shows that the time of flow decreases with increase in solvent volume, because the greater the solvent added to the solute, the lighter the resultant oil mixture. Moreover, for each blend there exists a mixture where the solvent tend to dissolve the solute completely, at this point the curve bends and at this transition stage, the resultant oil blends are neither too viscous nor too volatile.

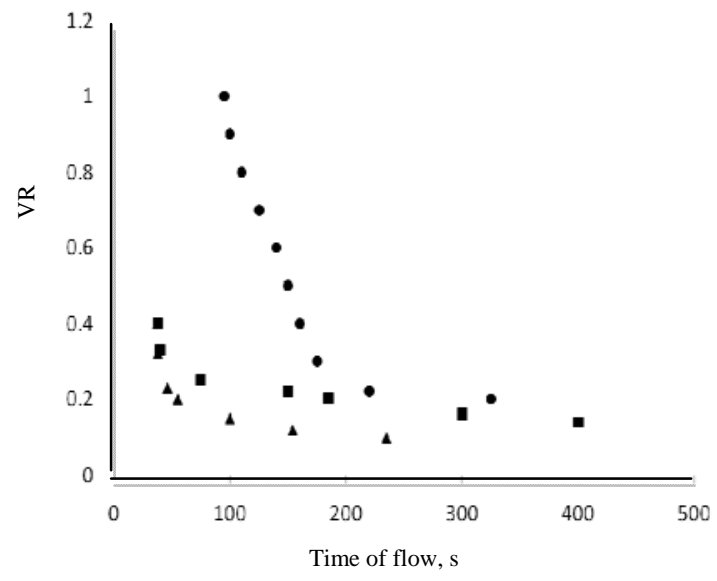

Figure 1. The effect of solvent volume on the time of flow for each oil blends ( $\boldsymbol{\Delta}$ Blend A; Blend B; $\bullet$ Blend C) 
The density dependence study on solvent volume shows a decrease in density with increasing solvent volume for all blends as shown in Figure 2. This is infact attributed to the fact that blends become less viscous as the solvent volume increases in a blend. Furthermore, the spreading diameters of blends $\mathrm{A}, \mathrm{B}$ and $\mathrm{C}$ are given on Table 1 . The droplets of the oil blends A, B and C on water were monitored at one minute interval which shows that increase in the volume fraction of the solvent causes an increase in the spreading diameter of the blends. Moreover, Gibbs free energy of mixing showed an increase in $-\Delta G^{\mathrm{m}}$ with increased solvent volume. Consequently, an increase in $\Delta S^{\mathrm{m}}$ was observed with increase in solvent volume. Hence, the spontaneity of energies of mixing is shown in Table 2. The extinction time of the mosquito larvae using different oil blends are shown in Table 3.

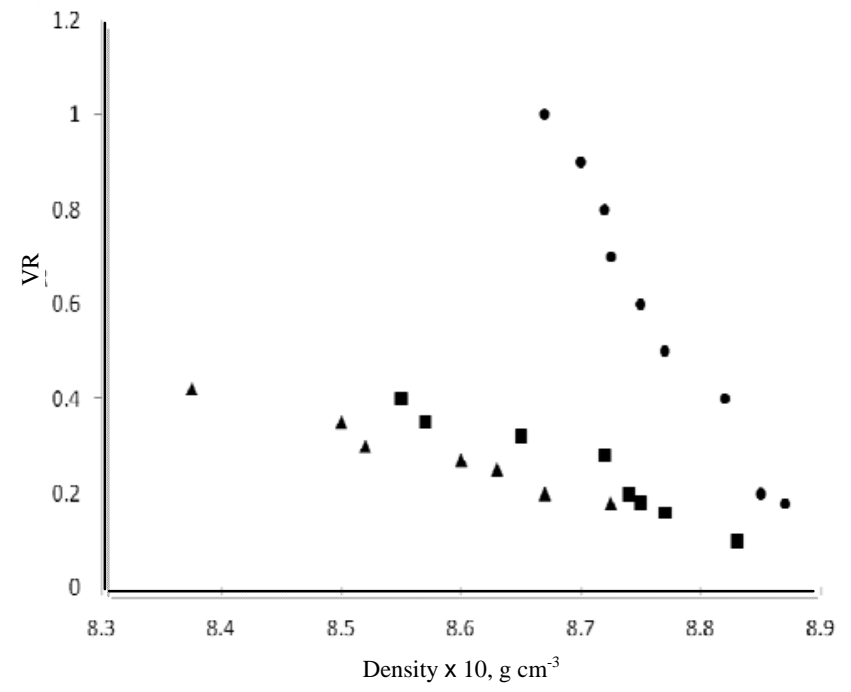

Figure 2. The effect of solvent volume on the density of oil blends after thorough mixing

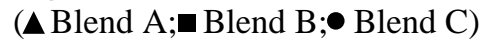

Table 1. Grades of oil blends with their corresponding densities, time of flow and spreading diameter at five minutes

\begin{tabular}{lccc}
\hline Grade of oil & Density, $\mathrm{g} \mathrm{cm}^{-3}$ & Time of flow, s & $\begin{array}{c}\text { Spreading diameter at } \\
\text { five minutes, cm }\end{array}$ \\
\hline Kerosine (SA) & 0.807 & 13 & 6.00 \\
Diesel (GD) & 0.857 & 15 & 5.60 \\
Used Engine oil & 0.888 & 513 & 5.40 \\
(GB1) & & & \\
Pure Engine oil & 0.889 & 552 & 5.20 \\
(GB2) & 0.882 & 14 & 10.20 \\
SA:GD (40:250) & 0.870 & 63 & 9.30 \\
SA:GB1 (50:250) & 0.864 & 141 & 8.60 \\
SA:GB2 (50:250) & 0.882 & 206 & 9.20 \\
GD:GB1 (50:250) & & & \\
\hline
\end{tabular}


Table 2. Effect of mass as a result of increasing solvent volume on energies of mixing $\left(-\Delta G^{\mathrm{m}}\right.$ and $\left.\Delta \mathrm{S}^{\mathrm{m}}\right)$

BLEND A

\begin{tabular}{ccccc}
\hline $\begin{array}{c}\text { Vol. of GBI, } \\
\mathrm{cm}^{3}\end{array}$ & $\begin{array}{c}\text { Vol. of SA, } \\
\mathrm{cm}^{3}\end{array}$ & $\begin{array}{c}-\Delta \mathrm{G}^{\mathrm{m}}, \\
\mathrm{kg} \mathrm{kJmo1}^{-1}\end{array}$ & $\begin{array}{c}\Delta \mathrm{S}^{\mathrm{m}}, \\
\mathrm{kg} \mathrm{kJK}^{-1} \mathrm{~mol}^{-1}\end{array}$ & $\begin{array}{c}\text { Mass of mixture } \\
\left(\mathrm{M}_{\mathrm{T}}\right) \mathrm{kg}\end{array}$ \\
\hline 250 & 0 & 0 & 0 & 0.222 \\
250 & 20 & 0.145 & 0.000489 & 0.237 \\
250 & 30 & 0.194 & 0.000650 & 0.245 \\
250 & 40 & 0.237 & 0.000790 & 0.235 \\
250 & 50 & 0.274 & 0.000920 & 0.261 \\
250 & 60 & 0.308 & 0.0010 & 0.268 \\
250 & 70 & 0.340 & 0.0011 & 0.274 \\
250 & 80 & 0.367 & 0.0012 & 0.282 \\
250 & 100 & 0.420 & 0.0014 & 0.298 \\
\hline
\end{tabular}

BLEND B

\begin{tabular}{ccccc}
\hline $\begin{array}{c}\text { Vol. of GB2, } \\
\mathrm{cm}^{3}\end{array}$ & $\begin{array}{c}\text { Vol. of SA, } \\
\mathrm{cm}^{3}\end{array}$ & $\begin{array}{c}-\Delta \mathrm{G}^{\mathrm{m}}, \\
\mathrm{kg} \mathrm{kJmo1}^{-1}\end{array}$ & $\begin{array}{c}\Delta \mathrm{S}^{\mathrm{m}}, \\
\mathrm{kg} \mathrm{kJK}^{-1} \mathrm{~mol}^{-1}\end{array}$ & $\begin{array}{c}\text { Mass of mixture } \\
\left(\mathrm{M}_{\mathrm{T}}\right) \mathrm{kg}\end{array}$ \\
\hline 250 & 0 & 0 & 0 & 0.220 \\
250 & 20 & 0.142 & 0.00047 & 0.237 \\
250 & 30 & 0.187 & 0.000626 & 0.244 \\
250 & 40 & 0.229 & 0.00075 & 0.251 \\
250 & 50 & 0.270 & 0.00090 & 0.259 \\
250 & 60 & 0.300 & 0.0010 & 0.265 \\
250 & 70 & 0.330 & 0.0011 & 0.272 \\
250 & 80 & 0.355 & 0.00118 & 0.278 \\
250 & 100 & 0.410 & 0.0013 & 0.292 \\
\hline
\end{tabular}

BLEND C

\begin{tabular}{ccccc}
\hline $\begin{array}{c}\text { Vol. of GBI, } \\
\mathrm{cm}^{3}\end{array}$ & $\begin{array}{c}\text { Vol. of GD, } \\
\mathrm{cm}^{3}\end{array}$ & $\begin{array}{c}-\Delta \mathrm{G}^{\mathrm{m}}, \\
\mathrm{kg} \mathrm{kJmo1}^{-1}\end{array}$ & $\begin{array}{c}\Delta \mathrm{S}^{\mathrm{m}}, \\
\mathrm{kg} \mathrm{kJK}^{-1} \mathrm{~mol}^{-1}\end{array}$ & $\begin{array}{c}\text { Mass of mixture } \\
\left(\mathrm{M}_{\mathrm{T}}\right) \mathrm{kg}\end{array}$ \\
\hline 250 & 0 & 0 & 0 & 0.222 \\
250 & 25 & 0.179 & 0.00060 & 0.243 \\
250 & 50 & 0.288 & 0.000968 & 0.246 \\
250 & 75 & 0.369 & 0.00122 & 0.285 \\
250 & 100 & 0.440 & 0.00146 & 0.300 \\
250 & 125 & 0.500 & 0.00167 & 0.325 \\
250 & 150 & 0.560 & 0.00187 & 0.346 \\
250 & 175 & 0.611 & 0.00120 & 0.367 \\
250 & 200 & 0.650 & 0.0022 & 0.387 \\
\hline
\end{tabular}

Table 3. Extinction time of the mosquito larvae using different blends

\begin{tabular}{lcc}
\hline \multicolumn{1}{c}{ Blend } & $\begin{array}{c}\text { Volume of blend used for } \\
\text { water surface coverage, } \mathrm{cm}^{3}\end{array}$ & Extinction time, min \\
\hline \multicolumn{1}{c}{ Diesel oil } & 150 & 8.00 \\
Kerosine: Diesel (50:250) & 100 & 13.00 \\
$\begin{array}{l}\text { Kerosine: Used Engine oil } \\
(50: 250)\end{array}$ & $<<300$ & $>>13.00$ \\
$\begin{array}{l}\text { Kerosine: Pure Engine oil } \\
(50: 250)\end{array}$ & $<<350$ & $>>13.00$ \\
\hline
\end{tabular}




\section{Conclusion}

Larvacidal mosquito control using less viscous and non-volatile oil blends has been found to be the most effective method of mosquito control, because mosquito larva were extinct within shortest possible time by deprivation from oxygen hence they easily die of asphyxia. Moreover, since mosquito larvae has been successfully eradicated, there would be no trace of pupa mosquito talk1ess of adult mosquitoes which are notorious and difficult to control.

\section{Reference}

1. $\quad$ Bruce-Chuvatt L J, J R Soc Med., 1981, 74(7), 531-536;

DOI:10.1177/014107688107400715

2. Fong Y L, Cadigan F C and Coatney G R, Trans R Soc Trop Med Hyg., 1971, 65(6), 839-840; DOI:10.1016/0035-9203(71)90103-9

3. Snow R W, Guerra C A, Noor A M, Myint H Y and Hay S I, Nature, 2005, 434(7030), 214-217; DOI:10.1038/nature03342

4. Beare N A, Taylor T E, Harding S P, Lewallen S and Molyneux M E, Am J Trop Moo Hyg., 2006, 75(5), 790-797.

5. Boivin M J, J Dev Behav Pediatr, 2002, 23(5), 353-364.

6. Saunders L, Principle of Physical Chemistry for Biology and Pharmacy, Second Edition, Oxford University, Press, 1971, 147; ISBN: 01985970539780198597056 